\section{Commentary: Less invasive, more incisions, more better?}

\author{
Ashish S. Shah, MD
}

Left ventricular assists devices (LVADs) offer a life-saving therapy for patients with both acute and chronic heart failure. Although the implantation technique is not complex, the management of these patients' condition remains challenging. Ultimately, the goals are improving quality and quantity of life. Appropriately, the field is focused on improving outcomes and this centers on improving device durability, developing algorithms to optimize device function, and eliminating the noxious problem of right ventricular (RV) failure. $\mathrm{Oh}$, and getting rid of the driveline would be great.

There is persistent interest in promoting sternal bone sparing approaches to implant LVADs. Some of this is driven by a desire to improve perioperative outcomes (eg, bleeding and mobility) and a belief that a sternal bone sparing approach will reduce the incidence of RV failure. So, the current study from 2 experienced centers (really 2 experienced surgeons) reviews outcomes between patients undergoing traditional median sternotomy and a sternal bone sparing approach. ${ }^{1}$ The authors demonstrate improvements in intensive care unit length of stay and reexploration for bleeding. Does this add to the almost 100 articles available on the topic? Although a laudable effort, the study fails to tackle the real potential benefits of a sternal bone sparing platform. First, there is no consistency in the approach. Cases that include extracorporeal life support, full cardiopulmonary bypass (CPB), and off-pump methods are lumped together. Patients who required valve intervention were excluded and CBP time was not even recorded by 1 contributing center. There is no information on pain control, which would be critical when adding a thoracotomy to

\footnotetext{
From the Department of Cardiac Surgery, Vanderbilt University Medical Center, Nashville, Tenn.

Disclosures: The author reported no conflicts of interest.

The Journal policy requires editors and reviewers to disclose conflicts of interest and to decline handling or reviewing manuscripts for which they may have a conflict of interest. The editors and reviewers of this article have no conflicts of interest.

Received for publication Dec 21, 2020; revisions received Dec 21, 2020; accepted for publication Dec 22, 2020; available ahead of print Dec 25, 2020.

Address for reprints: Ashish S. Shah, MD, Department of Cardiac Surgery, Vanderbilt University Medical Center, Vanderbilt Medical Center East, 1215 21st Ave, S, Suite 5025, Nashville, TN 37232 (E-mail: Ashish.s.shah@vumc.org).

J Thorac Cardiovasc Surg 2022;164:1919

$0022-5223 / \$ 36.00$

Copyright (c) 2020 by The American Association for Thoracic Surgery

https://doi.org/10.1016/j.jtcvs.2020.12.085
}

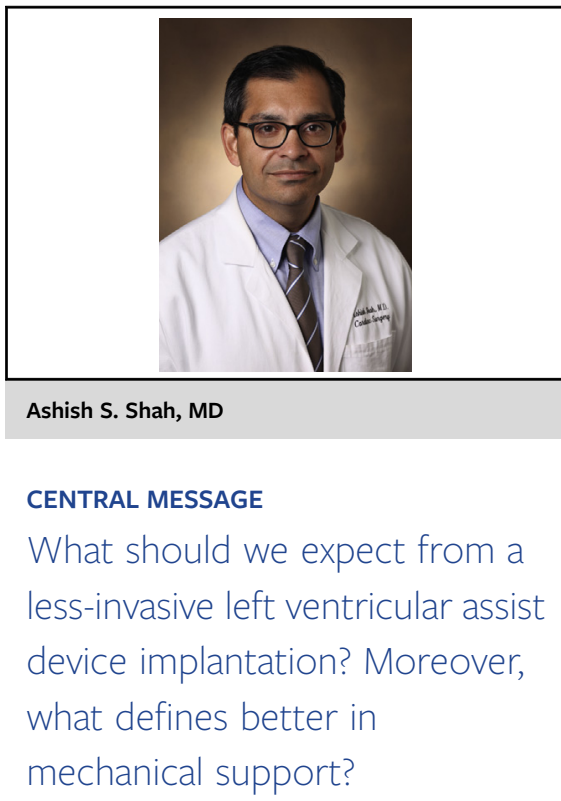

the mix. Moreover, there is very little information on perioperative management: Did the care change over time, which may have contributed to the improved outcomes? There will never be a randomized trial of sternotomy versus nonsternotomy approach in this group of patients, so creating a consistent approach is the first step to exploring its benefits. The authors miss an opportunity to examine RV function in detail. The current study saw no difference but without hemodynamic assessments. Finally, there are no functional outcomes that may favor a sternal sparing approach in the short term.

Our patients with heart failure want to live well without a driveline. This is a very different cohort from isolated mitral valve disease. So how do you change my surgeon's mind? Fundamental is addressing the real problems for these patients and then offering tools to solve them. As we saw with mitral valve surgery, developing instruments and devices to make the incisions smaller and the operation easier allows for the benefits to be clearer and the approach generalizable. But, the real question is whether some element of pericardial/sternal restraint improves postoperative and long-term RV function. Until we develop new tools to eliminate $\mathrm{CPB}$ and mediate RV dysfunction, selling minimally invasive LVAD implantation will be tough. Changing my surgeon's mind will be even tougher.

\section{Reference}

1. Jawad K, Sipahi F, Koziarz A, Huhn S, Kalampokas N, Albert A, et al Less-invasive ventricular assist device implantation: a multicenter study. J Thorac Cardiovasc Surg. 2022;164:1910-8.e4. 